\title{
Structural and functional characterization of a winter malting barley
}

\author{
M. Muñoz-Amatriaín, L. Cistué, Y. Xiong, H. Bilgic, A.D. Budde, M.R. Schmitt,
} K.P. Smith, P.M. Hayes and G.J. Muehlbauer

M. Muñoz-Amatriaín, Y. Xiong, H. Bilgic, K.P. Smith, G.J. Muehlbauer

Department of Agronomy and Plant Genetics, University of Minnesota, St. Paul, MN 55108, USA

A.D. Budde, M.R. Schmitt

Cereal Crop Research Unit, USDA-ARS, 502 Walnut St., Madison, WI 53726, USA

L. Cistué

EEAD (CSIC)

P.M. Hayes

Department of Crop and Soil Science, Oregon State University,

Corvallis, OR 97331, USA

Present address:

Y. Xiong

Pioneer Hi-Bred Int'l Inc., 810 Sugar Grove Ave, Dallas Center, IA 50063, USA

H. Bilgic

Department of Medicine/Rheumatology, University of Minnesota, Minneapolis, MN 55455 , USA

\section{Author for correspondence:}

G.J. Muehlbauer

Department of Agronomy and Plant Genetics, University of Minnesota, St. Paul, MN 55108, USA

Tel.: (+1) 612-625-6228

Fax: (+1) 612-625-1268

e-mail:mueh1003@umn.edu 


\begin{abstract}
The development of winter malting barley (Hordeum vulgare L.) varieties is emerging as a worldwide priority due to the numerous advantages of these varieties over spring types. However, the complexity of both malting quality and winter hardiness phenotypes makes simultaneous improvement a challenge. To obtain an understanding of the relationship between loci controlling winter hardiness and malt quality and to assess the potential for breeding winter malting barley varieties, we structurally and functionally characterized the six-row accession "88Ab536", a cold-tolerant line with superior malting quality characteristics that derives from the cross of NE76129/Morex//Morex. We used 4,596 SNPs to construct the haplotype structure of $88 \mathrm{Ab} 536$ on which malting quality and winter hardiness loci reported in the literature were aligned. The genomic regions determining malting quality and winter hardiness traits have been defined in this founder germplasm, which will assist breeders in targeting regions for marker-assisted selection. The Barley1 GeneChip array was used to functionally characterize 88Ab536 during malting. Its gene expression profile was similar to that of the archetypical malting variety Morex, which is consistent with their similar malting quality characteristics. The characterization of $88 \mathrm{Ab} 536$ has increased our understanding of the genetic relationships of malting quality and winter hardiness, and will provide a genetic foundation for further development of more cold-tolerant varieties that have malt quality characteristics that meet or exceed current benchmarks.
\end{abstract}

Keywords Barley, Hordeum vulgare L., Malting quality, Winter hardiness 


\section{INTRODUCTION}

Barley (Hordeum vulgare L.) is cultivated throughout the world and its greatest economic impact is linked to the malting and brewing industry. Malting is the controlled germination and early seedling growth of barley grain and mainly involves processes of carbohydrate and protein hydrolysis (Bamforth and Barclay 1993). Currently, around one-third of the barley crop is used for malting (Baik and Ullrich 2008). There is no single definition for malting quality since malting and brewing practices, and consumer preferences, vary around the world. For example, in North America, the major brewers tend to prefer 6-row malting varieties with higher protein and enzyme levels, while European brewers prefer malt obtained from 2-row barley varieties with higher starch content. A large number of parameters have been identified that contribute to malting quality, including: grain protein content, malt extract percentage, ratio of wort soluble protein to total malt protein, diastatic power, $\alpha$-amylase activity, and malt $\beta$-glucan content. Many of these traits are interrelated (Burger and LaBerge 1985; Fox et al. 2003) and an initial understanding of the genetic control of malting quality is just beginning to emerge.

The genetics of malting quality is complex (Hayes and Jones 2000). Many quantitative trait locus (QTL) studies have been carried out to dissect the genetics of malting and 154 malting-quality QTL associated with 18 traits have been recently summarized and placed on the Oregon Wolfe Barley (OWB) map (Szücs et al. 2009). However, only a few of these genes have been fully characterized (Hayes et al. 2003; Szücs et al. 2009). Large-scale gene expression technologies such as cDNA- and oligonucleotide-based arrays, and serial analysis of gene expression (SAGE) have proved to be useful to conduct transcript profiling during germination and malting (Lapitan et al. 2009; Potokina et al. 2002, 2004; Watson and Henry 2005; White et al. 2006), and to identify candidate genes for malting quality (Lapitan et al. 2009; Potokina et al. 2004, 2006).

As in the case of malting quality, the capacity to survive the winter (winter hardiness) also constitutes a complex phenotype that consists of three principal components: low-temperature (LT) tolerance, vernalization (VRN) response and 
photoperiod (PPD) sensitivity (Szücs et al. 2006). Two major QTL on chromosome 5H are associated with LT tolerance in barley, Frost resistance-H1 (Fr-H1) and Fr-H2 (Francia et al. 2004). $\mathrm{Fr}$-H2 is coincident with a cluster of at least $11 \mathrm{C}$-repeat binding factor $(C B F)$ genes, while $F r-H 1$ co-segregates with $V R N-H 1$, one of the three genes that control vernalization requirements in barley (Francia et al. 2004 and 2007; Galiba et al. 2009; Stockinger et al. 2007). It is still unknown whether $F r-H 1$ is a pleiotropic effect of $V R N-H 1$ or the effect of a physically linked gene (Galiba et al. 2009). VRN-H2, located on chromosome $4 \mathrm{H}$, and $V R N-H 3$, on chromosome $7 \mathrm{H}$, are the other two genes that affect VRN response (Hemming et al. 2008 and references therein). PPD-H1, the major determinant of photoperiod response under long-day conditions and located on chromosome $2 \mathrm{H}$ (Turner et al. 2005); and PPD-H2, which has been mapped to chromosome $1 \mathrm{H}$ and affects flowering time under short-day conditions (Faure et al. 2007), are the two genes that determine photoperiod sensitivity. Taken together, photoperiod, vernalization and LT tolerance pathways are highly interconnected (Galiba et al. 2009; Hemming et al. 2008; Karsai et al. 2008; Stockinger et al. 2007; Trevaskis et al. 2007).

Worldwide and especially in the USA, spring cultivars have been traditionally favored for malting. Due to the historical prevalence of spring malting barleys, the potential of winter malting varieties remains underexploited. Winter barley is an important crop alternative, providing advantages over the spring cultivars, such as increased yield and earlier maturation before the arrival of high temperature and water stress, which decreases the irrigation requirements (http://www.ambainc.org). For these and other reasons, the development of winter malting barleys is a high priority in the US. Recently, the American Malting Barley Association (AMBA) has recommended the first winter malting barley 'Charles', a 2-row variety (Obert et al. 2006), as a malting variety (http://www.ambainc.org/ni/2009 Recommended.pdf).

Although there has been progress developing winter hardy malting quality varieties, combining winter hardiness with acceptable malting characteristics remains a challenge. To meet the needs of both producers and industry, barley breeders must simultaneously maintain or improve malting quality while improving low temperature tolerance. Line 88 Ab536 was cooperatively developed by the USDA-ARS and the Idaho 
Agricultural Experiment Station as a six-row winter barley with superior malting quality characteristics (Wesenberg et al. 1998). 88Ab536 (Morex/Ne76129//Morex) was derived from the backcross of the Nebraska line Ne76129 (winter habit feed barley) with the Minnesota line Morex (spring habit malting barley), where Morex was the recurrent parent. This line is unique in that it combines the best attributes of both parents: it is cold tolerant and it has good malting quality characteristics. It was also the first and only US 6-row winter barley to pass the AMBA plant scale malt testing. Although 88Ab536 was not ultimately approved by AMBA due to reasons other than malting quality (flavor concerns in brewery testing), it has been extensively used as a parent in the Oregon State University breeding program and it figures in the pedigree of many advanced winter malting lines. Therefore, characterizing the founder genotype 88Ab536 through defining regions of the genome determining malting quality and winter hardiness traits would assist breeders in targeting regions for MAS and accelerate variety release.

In the present work, we report the characterization of the founder genotype $88 \mathrm{Ab} 536$ at both structural and functional levels. Our objectives were to (1) determine the haplotype structure of 88Ab536 and define its malting quality and winter hardiness footprints; and (2) evaluate the potential of developing winter malting varieties. 


\section{MATERIALS AND METHODS}

\section{Plant material and micromalting conditions}

The 6-rowed facultative line 88Ab536 and the 6-rowed spring cultivar Morex were used. 88Ab536 derives from a cross of NE76129/Morex//Morex. NE76129 was an experimental winter feed barley germplasm line from the University of Nebraska breeding program that was culled from the program and therefore not available for use in this study. Morex is a long established spring malting variety in the USA that appears in the pedigree of nearly all US six-row spring malting barley germplasm.

Grain samples of 88Ab536 and Morex were micromalted at the USDA-ARS Barley and Malt Laboratory of the Cereal Crops Research Units (CCRU) in Madison, Wisconsin, under standard CCRU micromalting conditions. Barley grains of 88Ab536 and Morex were steeped at $16^{\circ} \mathrm{C}$ for 24 and 29 hours, respectively, to achieve a uniform steep-out moisture of $45 \%$. Steeping involved alternating 4-hour periods of immersion in water and air-rest. The hydrated grains were transferred to germinators maintained at $17^{\circ} \mathrm{C}$ and $100 \%$ relative humidity in the dark immediately after steeping. Samples were collected at the end of the steep period ('out of steep') and after three days in the germinator ('3d of germination') (Figure 1). Three samples of each stage and genotype were harvested and placed in liquid nitrogen, and cleaned of emergent shoots and rootlets prior to microarray analysis. Finished malts derived from this experiment were subjected to malting quality analysis. A total of seven parameters commonly used to assess malt quality were measured following the standard ASBC (American Society of Brewing Chemists 2004) procedures: malt extract percentage (ME), grain protein content (GP), soluble protein $(\mathrm{SP})$, ratio of soluble protein to total malt protein $(\mathrm{S} / \mathrm{T})$, diastatic power (DP), $\alpha$-amylase activity (AA), and wort $\beta$-glucan concentration (BG). ME is one of the most important parameters for maltsters and brewers and measures the amount of soluble sugars and nitrogenous compounds obtained upon mashing malt into wort (Burger and LaBerge 1985). GP is a measure of the percentage of protein found in the grain and correlates with many of the other quality traits. SP is a measure of the amount of protein solubilized into wort after Congress mashing. $\mathrm{S} / \mathrm{T}$ is a measure of the extent of protein 
mobilization reflecting proteinase activity, while both AA and DP measure the carbohydrate-degrading enzymatic activities. The latter includes the combined action of alpha-amylase, beta-amylase and the rest of the amylolytic enzymes (Burger and LaBerge 1985). Finally, BG reflects the amount of beta-glucan present in wort after Congress mashing. Beta-glucan is a byproduct of cell wall breakdown and provides a measure of the extent of malt modification.

Malting quality data corresponding to a common site and to the locations where the two genotypes were grown for the expression profiling experiments was compiled from historical data (http://www.ars.usda.gov/Research/docs.htm?docid=16513) and is shown in Supplemental Table 1.

\section{Haplotype structure of 88Ab536 and QTL alignment}

88Ab536 and Morex were genotyped with three 1536-plex pilot Oligonucleotide Pool Assays (pilot OPAs; POPA1, POPA2, POPA3) using the Illumina GoldenGate BeadArray SNP detection platform. The genotyping assays were conducted at the Southern California Genotyping Consortium at the University of California, Los Angeles. The SNP loci are designated by their POPA numbers (e.g. 1_1311), where $1=$ the POPA number (POPA1 in this case) and the subsequent four digits correspond to the SNP order in the corresponding POPA. The locus designations can be directly referenced to assembly \#35 unigene numbers, and linkage map position of each locus can be determined by referring to the barley SNP consensus map at HarvEST (http://harvest.ucr.edu and http://www.harvest-web.org). Many of those SNPs did not "survive" the quality checks. Removal was based on low GenTrain score, missing data, and the lack of a consensus map position. Map orders and distances were transferred to an Excel spreadsheet, where each cell $=1 \mathrm{cM}$ (Supplemental Table 2). For generating the final graphical haplotype of 88Ab536, all loci with allele calls in common between 88Ab536 and Morex were assumed to trace to Morex and are shown in blue. Allele calls that were different between 88Ab536 and Morex were assumed to trace to NE76129 and are shown in red. Common allele calls between 88Ab536 and Morex located in regions assumed to come from NE76129 are colored in pink. Only one locus was retained for 
each group of co-segregating loci. If all loci in the co-segregating group traced to the same parent, a single locus was selected at random to represent the map coordinate. To maximize our ability to detect small genome introgressions (or introgressions of any size in extensive regions of monomorphism), when there were one or more alleles in a cluster tracing to alternative parents, the locus with an allele call different from the two flanking loci was selected. Cells without mapped loci are shown in white.

Malting quality and winter hardiness-related genes and/or QTL were assigned to map positions based on their presence in POPA-3 or their position was inferred based on the Oregon Wolfe Barley (OWB) integrated map (Szücs et al. 2009).

\section{RNA isolation, microarray hybridization and data analysis}

Total RNA from the twelve grain samples (two genotypes, two time points, and three replicates) was isolated using TRIzol ${ }^{\circledR}$ Reagent (Invitrogen, Carlsbad, CA) with phenol/chloroform/isoamyl alcohol (49:49:2) as a pre-treatment, and passed through RNeasy columns (Qiagen, Valencia, CA) for further clean up. RNA samples were quality assessed prior to labeling by means of an Agilent Bioanalyzer 2100 (Agilent Technologies, Palo Alto, CA). cDNA synthesis was conducted with $15 \mu \mathrm{g}$ of total RNA and T7-Oligo(dT) primer (Proligo, Boulder, CO) using the SuperScript Double-Stranded cDNA Synthesis Kit (Invitrogen, Carlsbad, CA). The cDNA was purified with the Affymetrix GeneChip Sample Cleanup Module (Affymetrix, Santa Clara, CA). To produce biotinylated cRNA, the cDNA was transcribed in vitro using the Enzo BioArray HighYield RNA Transcript Labeling Kit (Enzo Life Sciences, Farmingdale, NY) in the presence of biotinylated UTP and CTP. The biotin-labeled cRNA was purified with the Affymetrix GeneChip Sample Cleanup Module (Affymetrix, Santa Clara, CA). Labeled RNA $(15 \mu \mathrm{g})$ was chemically fragmented using the Affymetrix GeneChip Sample Cleanup Module (Affymetrix), and used for hybridization. The chip hybridizations, washes, and data acquisition were conducted at the Biomedical Image Processing Facility at the University of Minnesota following standard Affymetrix procedures. Data files are

available online from PlexDB's BarleyBase (experiment BB76, http://www.plexdb.org/modules/PD_browse/experiment_browser.php?expNo=BB76). 
Data analysis of GeneChip experiments was conducted using the software GeneSpring GX 9.0 (Silicon Genetics, Redwood City, CA, USA). Expression estimates were calculated using gcRMA algorithm implemented in GeneSpring. Quality control on samples was performed using the correlation coefficients among replicates which were over 0.98 , and the hierarchical clustering algorithm. Only probe sets with a signal intensity value greater than the $20^{\text {th }}$ percentile in all three replicates for at least one condition were considered reliable and included for subsequent analysis. Differentially expressed genes were identified by unpaired $t$-test with Benjamini-Hochberg false discovery rate (FDR) correction (Benjamini and Hochberg 1995). Analysis was done using a FDR adjusted p-value of 0.01 as the cutoff, followed by filtering for two-fold or greater changes. For annotation purposes, BLASTX $\left(\right.$ E-score cutoff $\left.=\mathrm{e}^{-10}\right)$ data was exported from HarvEST:Barley version 1.68 (http://harvest.ucr.edu).

\section{Sequencing of the mapped differentially expressed genes}

A total of six differentially expressed probe sets were sequenced in Morex and 88Ab536. Total gDNA was isolated from seeds of both genotypes using the DNeasy plant mini kit (Qiagen, Valencia, CA). Gene-specific primers were designed by Primer3 software based on the blast consensus sequence of each unigene and are shown in Supplemental Table 3. Amplification reactions were carried out in a $50 \mu$ l reaction containing $50 \mathrm{ng}$ of gDNA, 0.5 units of HotStarTaq DNA polymerase (Qiagen, Valencia, CA), 1x PCR buffer, $0.2 \mathrm{mM}$ of each $\mathrm{dNTP}$ and $0.3 \mu \mathrm{M}$ of each primer. PCR reactions were optimized to $95^{\circ} \mathrm{C}$ for $15 \mathrm{~min}, 33$ amplification cycles at $94^{\circ} \mathrm{C}$ for $1 \mathrm{~min}, 60^{\circ} \mathrm{C}$ for 1 $\min , 72^{\circ} \mathrm{C}$ for $1 \mathrm{~min}$, and a final extension of $10 \mathrm{~min}$ at $72^{\circ} \mathrm{C}$. Following PCR, products were purified using QIAquick PCR purification kit (Qiagen, Valencia, CA) and subsequently sequenced at the Biomedical Genomics Center (University of Minnesota). From 700 to 1900 base pairs were sequenced for each fragment (see Supplemental Table $3)$. 


\section{RESULTS}

\section{Malting quality characteristics}

To examine the malting quality characteristics of 88Ab536 and Morex, seven primary parameters used to assess malting quality were measured (Table 1). Mean values corresponding to four years of submissions from a common site (Aberdeen, ID) are presented to provide a general malt quality characterization of both genotypes in comparison to the AMBA ideal commercial malt criteria for 6-row barley (Table 1A). As had been judged previously during AMBA evaluation, 88Ab536 generally meets or exceeds the established malt quality benchmarks, as does Morex. Both lines had slightly lower ME than the "ideal" and higher than desired beta-glucan content (BG) when malted according to the standard conditions at the CCRU. The similarity of the averaged quality characteristics is remarkable. Because the Morex and 88Ab536 barleys used for the expression profiling were not grown at the same location, historic data of each genotype produced at comparable locations are detailed in Supplemental Table 1 showing locationyear variation in malting quality attributes. Values for the seven primary qualityassurance parameters in finished malt for the Morex and 88Ab536 series (three malting replicates each) used in microarray experiments (Table 1C) are compared to the averages of the historic values from the experimental locations in Table 1B. The data show that the malting quality performance of the Morex and 88Ab536 samples used in the microarray experiments is representative of the lines' normal malting quality performance measured over a number of years.

\section{Structural characterization of 88Ab536}

\section{Haplotype structure}

To construct the haplotype structure of 88Ab536, we genotyped this line and the recurrent parent Morex with the SNPs available from POPA 1, 2 and 3 (http://www.barleycap.org). Many of these 4,596 barley SNP markers were eliminated 
when both genotypes were compared in order to generate a more precise graphical haplotype (see "materials and methods" for detailed information). Therefore, a total of 723 unique SNP-mapped loci, together with the 372 gaps with no mapped loci, resulted in a final map length of $1,095 \mathrm{cM}$ (Figure 2).

Genome regions where SNP loci were polymorphic between 88Ab536 and Morex were assumed, with confidence, to trace to NE76129. Monomorphic loci located in polymorphic regions were also considered to come from NE76129 since it is unlikely that two rounds of crossing would produce the recombination events to result in small regions of Morex alleles with a NE76129 block (Devaux et al. 1995; Sall et al. 1990). Monomorphic loci between the two genotypes were assumed to come from Morex. This assumption involves a certain degree of error since there could be common allele calls in regions where the two genotypes differ. However, 542 of the 723 loci in 88Ab536 had allele calls common to Morex, giving an estimated recurrent parent genome content of $74.97 \%$. This value agrees with the expected value of $75 \%$ derived from a single backcross.

\section{Malting quality QTL}

Malting quality QTL reported in the literature were assigned map positions on the 88Ab536 graphical haplotype based on the integrated OWB map (Szücs et al. 2009). In this study, we focus on 40 of the 55 QTL for which Szücs et al. (2009) assigned precise map coordinates based on the presence of markers in common between the original QTL report and the integrated OWB map (Table 2). Only the QTL for the seven traits for which we have phenotypic measurements (Table 1) were placed on the map. As shown in Figure 2, chromosomes $4 \mathrm{H}$ and $5 \mathrm{H}$ contained the highest number of QTL (8), while chromosome $6 \mathrm{H}$ had the least number of them (2).

Seventy percent of the malting-quality QTL were located in regions where 88Ab536 alleles trace to Morex. Alpha-amylase (AA) activity and grain protein (GP) content were the parameters with the most QTL (12) placed on the haplotype structure. However, while most of the AA QTL were placed on regions derived from Morex, four of the GP QTL were located in genome regions tracing to NE76129. GP exhibits the 
highest number of QTL tracing to the feed barley parent. Diastatic power (DP) was also a well-represented trait, with seven QTL, of which three were located in genomic regions that traced to NE76129. There were five QTL for wort $\beta$-glucan content (BG), two of them traced to the feed barley parent. Three malt extract (ME) QTL were placed on the map, two of them on regions derived from Morex. Finally, the only QTL for the ratio of soluble protein to total malt protein $(\mathrm{S} / \mathrm{T})$ was located on chromosome $3 \mathrm{H}$ in a region tracing to the malting barley parent.

\section{Winter hardiness QTL}

Previously identified QTL associated with the capacity to overwinter were also aligned on the haplotype structure of 88Ab536 (Table 2). $\mathrm{Fr}$-H1 and $\mathrm{Fr}-\mathrm{H} 2$, the main LT tolerance QTL (Francia et al. 2004), were located in an introgressed NE76129 region of chromosome $5 \mathrm{H}$ (Figure 2). The candidate gene for $\mathrm{Fr}-\mathrm{H} 2$ is one or more members of two physically linked clusters of at least $11 C B F$ genes (Francia et al. 2007; Galiba et al. 2009; Skinner et al. 2005) whose expression is regulated by Fr-H1 (Stockinger et al. 2007). Fr-HI is not only important for LT tolerance at the vegetative stage, but also for reproductive-stage frost tolerance (Reinheimer et al. 2004). Flt-2L, located in a region on chromosome $2 \mathrm{H}$ tracing to the cold-tolerant parent NE76129, is the other locus involved in this phenomenon of LT tolerance at the vegetative stage (Chen et al. 2009; Reinheimer et al. 2004).

$V R N-H 1$ (synonymous with $H v B M 5 A$ ), one of the principal genes controlling VRN response in barley, is the candidate gene for Fr-H1 (Stockinger et al. 2007; von Zitzewitz et al. 2005). $V R N-H 2$, encoding a zinc finger-CCT transcription factor that is a repressor of flowering (Yan et al. 2004), is the other key gene mediating VRN response. It is a complete $V R N-H 2$ deletion that makes $88 \mathrm{Ab} 536$ facultative (von Zitzewitz et al. 2005; Szücs et al 2007). Both $V R N-H 1$ and $V R N-H 2$ were located in regions derived from NE76129 (Figure 2). Finally, $V R N-H 3$, which encodes a promoter of the flowering orthologue to the Arabidopsis FLOWERING LOCUS T (FT) gene (Faure et al. 2007; Yan et al. 2006), was placed on a genomic region tracing to Morex (Figure 2). There is limited 
allelic variation at the $V R N-H 3$ locus in most cultivated barley germplasm (Yasuda et al. 1993; Yan et al. 2006).

Regarding the two loci involved in photoperiod sensitivity, $P P D-H 1$ and $P P D$ $H 2$, both of them were derived from the spring-variety Morex (Figure 2). The fact that $88 \mathrm{Ab} 536$ carries the spring allele of $H v F T 3$, the candidate gene for PPD-H2, indicates that this line is not sensitive to short-day photoperiods (Faure et al. 2007). As in the case of $P P D-H 2$, the spring recessive allele at $P P D-H 1$ confers insensitivity to long-day conditions (Turner et al. 2005).

\section{Functional characterization}

To functionally characterize 88Ab536, we used the Barley1 GeneChip (Close et al. 2004) to identify the differentially expressed genes between this line and the recurrent parent Morex at two different time points of the malting process: "out of steep" and " $3 \mathrm{~d}$ of germination" (Figure 1). Using a FDR adjusted p-value of 0.01 and filtering by twofold or greater changes, statistical analysis resulted in 40 differentially expressed transcripts at time point "out of steep" (Table 3) and 21 at " $3 \mathrm{~d}$ of germination" (Table 4). Five of these genes were found to be differentially expressed at both time points, therefore resulting in a total of 56 genes with significant differences in the expression level between 88Ab536 and Morex. Most of these genes (67.8\%) had higher expression levels in 88Ab536 compared to Morex.

Over $30 \%$ of these 56 genes had no match to any sequence in the UniProt, Rice and Arabidopsis databases, or encoded proteins with unknown function. Regarding the classified gene transcripts, most of them coded for proteins with different functions. Interestingly, we detected six histones, five of them up-regulated in 88Ab536 at time point " $3 \mathrm{~d}$ of germination" (Table 4). Three retrotransposon proteins up-regulated in 88Ab536 at "out of steep" (Table 3), and three jasmonate-induced proteins, two of them up-regulated at " $3 \mathrm{~d}$ of germination" (Table 4), were also found among the most numerous differentially expressed genes.

A total of seven of the differentially expressed genes were previously mapped to the barley SNP consensus map (http://harvest.ucr.edu) and their map locations are shown 
in Tables 3 and 4. Two of them (HS05N24u_s_at and Contig10883_at) mapped to the same position and had the same unigene sequence, indicating that they are the same gene. These 6 genes were placed on the haplotype structure of 88Ab536. As shown in Figure 2, all of them were located in regions tracing to Morex, which suggests that other genes located in regions introgressed from NE76129 might control their expression (transfactors) (reviewed by Kliebenstein 2009). To further explore this possibility, we sequenced these six genes in 88Ab536 and Morex. Sequencing showed that both genotypes had the same sequence for all the six mapped genes (data not shown). 


\section{DISCUSSION}

The development of winter malting barley varieties has emerged as a new priority for breeders. Winter varieties exhibit considerable advantages over spring barleys, including higher yield, lower irrigation requirements and possibility of production in areas where certain fungal diseases (e.g. Fusarium Head Blight) are not as serious a risk. However, the genetic control of malting quality and winter hardiness is extremely complex and is just beginning to be unraveled. Thus, developing winter malting varieties is difficult due to the lack of knowledge and the complexity of the traits. $88 \mathrm{Ab536}$ is a winter barley with superior malting quality characteristics that has been extensively used as a founder genotype for developing winter malting varieties. To obtain an understanding of the genetic relationship between malting quality and winter hardiness, we characterized 88Ab536 using structural (4,608 pilot OPA SNP markers) and functional (22k Affymetrix Barley1 GeneChip) genomic resources. This study provided the opportunity to (1) identify the genetic footprints of malting quality and winter hardiness; and (2) to assess the potential of developing winter malting barley varieties.

\section{Malting quality footprints}

88Ab536 exhibits malting quality characteristics comparable to its malting parent Morex (Table 1A), generally meeting the ideal commercial malt criteria established by AMBA (http://www.ambainc.org/ni/Guidelines.pdf). Since NE76129, the cold-tolerant parent of $88 \mathrm{Ab} 536$, is a feed barley with no reported favorable malting quality attributes, most favorable alleles for malting quality could be reasonably assumed to trace to the malting cultivar Morex. The high percentage of the malting quality QTL (70\%) located in 88Ab536 regions tracing to Morex supports this assumption. There are, of course, examples in literature of favorable malting quality alleles tracing to parents with overall unfavorable phenotypes (Clark et al. 2003; Hayes et al. 1993).

Focusing on the specific traits, the allele at one out of the three ME QTL on the graphical haplotype was derived from NE76129 (Figure 2). As the 88Ab536 values for ME were similar to the archetypical malting cultivar Morex (Table 1A), the NE76129 
allele on chromosome $1 \mathrm{H}$ appears to have a neutral effect on the trait. In the case of GP, up to four of the 12 QTL were located in regions introgressed from NE76129 on chromosomes $1 \mathrm{H}, 2 \mathrm{H}$ and $7 \mathrm{H}$ (Figure 2). As in the case of ME, given the GP values for 88Ab536 and Morex (Table 1A), these four NE76129 alleles do not affect the trait. S/T values were also quite similar between 88Ab536 and Morex (Table 1A), which agrees with the observation that the only S/T QTL aligned on the haplotype structure was located in a region tracing to Morex (Figure 2). For DP, three of the 7 QTL were located in genome regions of $4 \mathrm{H}, 6 \mathrm{H}$ and $7 \mathrm{H}$ that traced to the feed barley parent. The QTL on chromosome $4 \mathrm{H}$ is coincident with the $\beta$-amylase gene Bmyl (Kreis et al. 1988). Resequencing of Bmyl in 88Ab536 confirmed the presence of an Sd4-type allele whereas Morex is $S d 1$ (Filichkin et al. submitted). No direct effects of Bmyl allele types on enzyme thermostability, enzyme activity, and diastatic power were found in an extensive characterization of North American six-row varieties and breeding lines, including 88Ab536 and Morex (Filichkin et al. submitted). Therefore, it is not possible to define the 4H DP allele tracing to NE76129 as positive or negative. However, the overall lower DP of 88Ab536 compared to Morex (Table 1A) suggests that substitution by the Morex alleles at one or more loci could be advantageous. Although only two of the twelve 88Ab536 AA QTL traced to NE76129 (Figure 2), their substitution by the Morex allele on chromosomes $1 \mathrm{H}$ and $5 \mathrm{H}$ could potentially improve AA (Table $1 \mathrm{~A}$ ). BG is the only malting quality trait in $88 \mathrm{Ab} 536$ that, due to its high value, did not fit specifications (Table 1A). High BG values are considered undesirable since they reflect a decreased level of modification during malting, leading to wort filtration difficulties (Bamforth and Barclay 1993). Two out of the three BG QTL were located in 88Ab536 genome regions tracing to NE76129 (Figure 2). Although Morex had lower BG values (Table 1A), they are still too high for ideal performance at the brewery. As a consequence, future breeding effort should be directed towards the targeting and introgression of additional low BG alleles.

Samples of 88Ab536 and Morex from two key stages ('out of steep' and ' $3 \mathrm{~d}$ of germination') in the malting process showed essentially identical morphologies (Figure 1). Examination of their transcriptomes at those stages found that only a few genes were 
differentially expressed (Tables 3 and 4). This similarity in the gene expression profiles of both genotypes is consistent with the similarity in their malting quality characteristics.

None of the 56 differentially expressed genes corresponded to proteins associated with mobilization of the major seed starch and storage protein reserves or cell wall carbohydrates during malting (Hayes et al. 2003; Potokina et al. 2004; White et al. 2006). One transcript (Contig13847_s_at) that was up-reguated in 88Ab536 compared to Morex at 'out of step' codes for a subtilisin-like serine endoprotease (Table 3). Serine endoproteinases shown to degrade malt beta amylase have been hypothesized to indirectly affect DP (Schmitt and Budde 2007; Schmitt and Marinac 2008). However, no conclusive role in determining malting quality has been shown for the serine endoprotease corresponding to this transcript.

A few transcripts coding for histones, retrotransposon and jasmonate-induced proteins were found among the differentially expressed genes, most of them up-regulated in 88Ab536 compared to Morex (Tables 3 and 4). Differences in expression levels of histones have been found during seed germination in barley (Potokina et al. 2002) and their presence in this study could be due to differences in the cell division cycle activity between both genotypes. Many genes recently identified by Lapitan et al. (2009) as correlated to malting quality phenotypes coded for proteins involved in defense and stress response, among which jasmonate-induced proteins were the most abundant ones. Other previous studies on germinating seeds also identified these proteins (Watson and Henry, 2005; White et al. 2006). Together with the three jasmonate-induced proteins found to be differentially expressed in 88Ab536, two genes encoding a heat shock factor protein HSF8 and an oxalate oxidase GF-2.8 precursor were up- and down-regulated in 88Ab536 at "out of steeping" (Table 3) were also found in the study of Lapitan et al. (2009).

Six of the differentially expressed genes had been previously mapped to the SNP consensus map and were placed on the haplotype structure (Figure 2). Interestingly, all of them were located on regions tracing to Morex, which suggested that these genes are regulated in trans (Kliebenstein 2009). The sequencing of these 6 genes in both 88Ab536 and Morex supported this assumption since both sequences were identical for all the mapped genes. 


\section{Winter hardiness footprints}

Since Morex is a very susceptible variety to winter injury, most favorable alleles of $88 \mathrm{Ab536}$ for LT tolerance could be reasonably assumed to trace to NE76129. The graphical haplotype supported this assumption since the $\mathrm{Fr}-\mathrm{H} 1 / \mathrm{VNR}-\mathrm{H} 1$ and $\mathrm{Fr}-\mathrm{H} 2 / \mathrm{CBF}$ regions on $5 \mathrm{H}$ in $88 \mathrm{Ab} 536$ traced to NE76129 (Figure 2). This also provides additional evidence for the importance of this genomic region in cold tolerance. The chromosome 4HL introgression accounted for the facultative growth habit of 88Ab536 - it includes a complete deletion of $V R N-H 2$ (von Zitzewitz et al. 2005; Szücs et al 2007). The fact that Ne76129 was facultative due to a deletion of this locus was not entirely unexpected since we have also found $V R N-H 2$ deletion lines in germplasm arrays where most individuals are $V R N-H 2$ dominant (i.e. the gene is present) (Szücs et al 2008). The genomic region including $V R N-H 3$ allele traced to Morex (Figure 2). The functionally recessive (winter allele) allele is present in most cultivated barley accessions; the dominant "spring" alleles confer very early flowering. (Yasuda et al. 1993; Yan et al. 2006). Therefore, a "Morex" allele at this locus would not be unexpected in a "winter" genotype. The Flt-2L QTL involved in LT tolerance at the reproductive stage (Chen et al. 2009; Reinheimer et al. 2004) was placed on the introgressed NE76129 region of chromosome $2 \mathrm{H}$. Although in principle this is a distinct phenomenon and this region has not been reported in vegetative LT tolerance, interestingly it has been retained in 88Ab536, suggesting an effect of the LT tolerance at the vegetative stage. Both $P P D-H 1$ and $P P D-H 2$ were located in genomic regions where 88Ab536 traced to Morex (Figure 2). The late-flowering PPD-H1 spring allele is recessive due to a mutation in the CCT domain and it is particularly important when a variety is sown in the spring since the long-day insensitivity conferred by this allele allows a prolonged growing period and, consequently, a higher yield (Turner et al. 2005). The fact that $88 \mathrm{Ab536}$ also has the spring allele at PPD-H2 (Szücs et al 2008), which confers insensitivity to short days (Faure et al. 2007), is not a desirable feature for a winter barley. Short-day photoperiod sensitivity would be better for a fall-sown variety because it will keep plants at the vegetative state longer (Pan et al. 1994), perhaps through the maintenance of the expression of genes conferring low-temperature tolerance (Fowler et al. 2001). Therefore, the substitution of this spring allele by the winter one 
would be desirable for greater cold tolerance that allows expanding the potential winter malting barley acreage.

\section{Future prospects for developing winter malting varieties}

The simultaneous alignment of the coincident malting quality and winter hardiness QTL reported in literature on the foundation line 88Ab536 allows the identification of the alleles that are critical for the development of new winter malting barley varieties. Although 88Ab536 possesses most of the alleles that are needed for a cold-tolerant variety that fits commercial malting quality criteria, there is still room for improvement. Regarding winter hardiness, 88Ab536 carries the favorable winter alleles for the two main genomic regions involved in cold tolerance ( $\mathrm{Fr}-\mathrm{H} 1$ and $\mathrm{Fr}-\mathrm{H} 2)$. Maintaining the 88Ab536 haplotype for this region of 5H will ensure a minimum level of cold tolerance. However, the level of cold tolerance displayed by 88Ab536 is still not sufficient to allow commercial production in all target environments. Ongoing efforts will reveal additional genomic regions involved in cold tolerance and/or alternative alleles at Fr-H1 and/or Fr-H2. The facultative growth habit of $88 \mathrm{Ab536}$ is advantageous. Facultative varieties may be sown either in fall or spring, simplifying variety distribution and giving the option of re-planting with the same variety in the spring. Under controlled environmental conditions, facultative germplasm is amenable to accelerated cycles of breeding as it does not require a vernalization treatment (typically six weeks) between each generation. However, 88Ab536 has the spring allele at $P P D-H 2$, the major photoperiod-response gene responsible for the short-day sensitivity (Figure 2). Its substitution by the winter allele would be feasible and desirable to ensure that varieties do not initiate a vegetative-to-reproductive transition too early in the growing season. The favorable allelic state at $P P D-H 1$ will vary depending on target environments. One of the advantages of winter varieties in many environments is that they ripen prior to the onset of maximum summer temperatures. Under such situations, long-day sensitivity may be desirable. In environments where moisture is not limiting and full yield potential can be realized, long-day insensitivity would be desirable. Concerning malt quality characteristics, 88Ab536 approaches commercial expectations for malting quality 
parameters. The line was not commercialized due to beer flavor issues. No data are available for genetic dissection of beer flavor. Industry preferences and specifications for GP and DP may change with time. However, it is likely that ME cannot be too high and BG too low. The favorable allele for ME tracing to NE76129 may allow for future improvements in ME. Marker-assisted selection should be particularly useful for breaking the repulsion linkage between $\mathrm{BG}$ and winter hardiness due to the proximity of the $\mathrm{BG}$ QTL with $\mathrm{Fr}$-H1 and $\mathrm{Fr}$-H2 (Figure 2). Since QTL mapping studies generally underestimate the number of QTL associated with quantitative traits, there are likely other undetected loci important for quality that will be segregating in breeding crosses made with 88Ab536. Thus, MAS at QTL for the favorable alleles identified in this study that are not linked in repulsion followed by phenotypic selection, should take advantage of both mapped and unmapped loci and result in improved malting quality and winter hardiness.

88Ab536 is testimony to the power of persistent plant breeding and phenotypic selection. These efforts have made possible this first and only six-row selection that combines winter hardiness and an AMBA-approved level of malting quality. Its structural and functional characterization has allowed us to understand how this breakthrough was achieved, letting us to create a template (footprint) for future variety development efforts by ensuring that the desired alleles are maintained at key regions of the genome. This will also facilitate the introgression of alleles determining other essential traits (e.g. agronomic performance, disease resistance) while maximizing the likelihood of meeting threshold values for winter hardiness and malting quality. The breeding approaches for future improvement will depend upon available resources, breeding strategies within individual programs, and accessibility to cheap, robust and high-throughput markers. 
Acknowledgements We thank Dr. Darrell Wesenberg for the persistence and skillful plant breeding that led to the development of $88 \mathrm{Ab} 536$. We also appreciate the resources provided by the University of Minnesota Supercomputing Institute. L. Cistué is recipient of a Senior Research Fellow at the Oregon State University from the Spanish Ministry of Science and Innovation. This research was supported by grants from the USDA-CSREES United States Barley Genome Project to GJM and KPS. 


\section{REFERENCES}

American Society of Brewing Chemists. (2004) Methods of Analysis, 9th ed. Barley-7C Protein by combustion; Malt-4 Extract, -6A Diastatic Power, -7A Alpha Amylase, 17 Protein in unhopped wort by spectrophotometry, $-18 \beta$-glucan in congress wort by fluorescence. The Society, St. Paul, MN

Baik B-K, Ullrich SE (2008) Barley for food: Characteristics, improvement and renewed interest. J Cereal Sci 48:223-242

Bamforth CW, Barclay AHP (1993) Malting technology and the uses of malt. In: McGregor A, Bhatty RS (eds) Barley: chemistry and technology. American Association of cereal Chemists, St. Paul, pp 297-354

Benjamini Y, Hochberg Y (1995) Controlling the false discovery rate: A practical and powerful approach to multiple testing. J R Stat Soc Ser B 57:289-300

Burger WC, LaBerge DE (1985) Malting and Brewing Quality. In: Rasmusson DC (ed) Barley. Agronomy Monograph No. 26, ASA-CSSA-SSSA, Madison, WI, pp 367401

Chen A, Reinheimer J, Brûlé-Babel A, Baumann U, Pallotta M, Fincher GB, Collins NC (2009) Genes and traits associated with chromosome $2 \mathrm{H}$ and $5 \mathrm{H}$ regions controlling sensitivity of reproductive tissues to frost in barley. Theor Appl Genet 118:1465-1476

Clark S, Hayes PM, Henson CA (2003) Effects of single nucleotide polymorphisms in $\beta$ amylase 1 alleles from barley on functional properties of the enzymes. Plant Physiol Biochem 41:798-804

Close TJ, Wanamaker S, Caldo RA, Turner SM, Ashlock DA, Dickerson JA, Wing RA, Muehlbauer GJ, Kleinhofs A, Wise RP (2004) A new resource for cereal genomics: 22K barley GeneChip comes of age. Plant Physiol 134:960-968

Devaux D, Kilian A, Kleinhofs A (1995) Comparative mapping of the barley genome with male and female recombination-derived, doubled haploid populations. Mol Gen Genet 249:600-608

Faure S, Higgins J, Turner A, Laurie DA (2007) The FLOWERING LOCUS T-Like gene family in barley (Hordeum vulgare). Genetics 176:599-609 
Fowler DB, Breton G, Limin AE, Mahfoozi S, Sarhan F (2001) Photoperiod and temperature interactions regulate low-temperature-induced gene expression in barley. Plant Physiol 127:1676-1681

Fox GP, Panozzo JF, Li CD, Lance RCM, Inkerman PA, Henry RJ (2003) Molecular basis of barley quality. Aust J Agric Res 54:1081-1101

Francia E, Rizza F, Cattivelli L, Stanca AM, Galiba G, Tóth B, Hayes PM, Skinner JS, Pecchioni N (2004) Two loci on chromosome 5H determine low-temperature tolerance in a 'Nure' (winter) × 'Tremois' (spring) barley map. Theor Appl Genet 108:670-680

Francia E, Barabaschi D, Tondelli A, Laidò G, Rizza F, Stanca AM, Busconi M, Fogher C, Stockinger EJ, Pecchioni N (2007) Fine mapping of a HvCBF gene cluster at the frost resistance locus Fr-H2 in barley. Theor Appl Genet 115:1083-1091

Galiba G, Vágújfalvi A, Li C, Soltész A, Dubcovsky J (2009) Regulatory genes involved in the determination of frost tolerance in temperate cereals. Plant Sci 176:12-19

Hayes PM, Liu BH, Knapp SJ, Chen F, Jones B, Blake T, Frankckowiak J, Rasmusson D, Sorrells M, Ullrich SE, Wesenberg D, Kleinhofs A (1993) Quantitative trait locus effects and environmental interaction in a sample of North American barley germ plasm. Theor Appl Genet 87:392-401

Hayes PM, Jones BL (2000) Malting quality from a QTL perspective. In: $8^{\text {th }}$ International Barley Genetics Symposium, Adelaide Convention Centre, Adelaide, South Australia 8:99-105

Hayes MP, Castro A, Marquez-Cedillo L, Corey A, Henson C, Jones BL, Kling J, Mather D, Matus I, Rossi C, Sato K (2003) Genetic diversity for quantitatively inherited agronomic and malting quality traits. In: von Bothmer R, van Hintum T, Knüpffer $\mathrm{H}$, Sato K (eds) Diversity in Barley (Hordeum vulgare). Amsterdam, The Netherlands, Elsevier Science, pp 201-226

Hemming MN, Peacock WJ, Dennis ES, Trevaskis B (2008) Low-temperature and daylength cues are integrated to regulate FLOWERING LOCUS T in barley. Plant Physiol 147:355-366 
Karsai I, Szűcs P, Kőszegi B, Hayes PM, Casas A, Bedő Z, Veisz O (2008) Effects of photo and thermo cycles on flowering time in barley: a genetical phenomics approach. J Exp Bot 59:2707-2715

Kliebenstein D (2009) Quantitative genomics: analyzing intraspecific variation using global gene expression polymorphisms or eQTLs. Annu Rev Plant Biol 60:93-114

Kreis M, Williamson M, Shewry PR, Sharp P, Gale M (1988) Identification of a second locus encoding $\beta$-amylase on chromosome 2 of barley. Genetical Res 51:13-16

Lapitan NLV, Hess A, Cooper B, Botha AM, Badillo D, Iyer H, Menert J, Close TJ, Wright L, Hanning G, Tahir M, Lawrence C (2009) Differentially expressed genes during malting and correlation with malting quality phenotypes in barley (Hordeum vulgare L.). Theor Appl Genet 118:937-952

Obert DE, Wesenberg DM, Burrup DE, Jones BE, Erickson CA (2006). Registration of 'Charles' barley. Crop Sci 46:468-469

Pan A, Hayes PM, Chen F, Chen THH, Blake T, Wright S, Karsai I, Bedö Z (1994) Genetic analysis of the components of winterhardiness in barley (Hordeum vulgare L.). Theor Appl Genet 89:900-910

Potokina E, Sreenivasulu N, Altschmied L, Michalek W, Graner A (2002) Differential gene expression during seed germination in barley (Hordeum vulgare L.). Funct Integr Genomics 2:28-39

Potokina E, Caspers M, Prasad M, Kota R, Zhang H, Sreenivasulu N, Wang M, Graner A (2004) Functional association between malting quality trait components and cDNA array based expression patterns in barley (Hordeum vulgare L.). Mol Breeding $14: 153-170$

Potokina E, Prasad M, Malysheva L, Röder MS, Graner A (2006) Expression genetics and haplotype analysis reveal cis regulation of serine carboxypeptidase I (Cxp1), a candidate gene for malting quality in barley (Hordeum vulgare L.). Funct Integr Genomics 6:25-35

Reinheimer JL, Barr AR, Eglinton JK (2004) QTL mapping of chromosomal regions conferring reproductive frost tolerance in barley (Hordeum vulgare L.). Theor Appl Genet 109:1267-1274 
Sall T, Flink J, Bengtsson BO (1990) Genetic control of recombination in barley. I. Variation in recombination frecuency measured with inversion heterozygotes. Hereditas 112:171-178

Schmitt MR, Budde AD (2007) Improved methods for high-throughput extraction and assay of green barley malt proteinase activity facilitating examination of proteinase activity across large-scale populations. Cereal Chem 84:313-319

Schmitt MR, Marinac L (2008) Beta-amylase degradation by serine endoproteinases from green barley malt. J Cereal Sci 47:480-488

Skinner JS, von Zitzewitz J, Szücs P, Marquez-Cedillo L, Filichkin T, Amundsen K, Stockinger EJ, Thomashow MF, Chen THH, Hayes PM (2005) Structural, functional, and phylogenetic characterization of a large CBF gene family in barley. Plant Mol Biol 59:533-551

Stockinger EJ, Skinner JS, Gardner KG, Francia E, Pecchioni N (2007) Expression levels of barley $\mathrm{Cbf}$ genes at the Frost resistance-H2 locus are dependent upon alleles at $\mathrm{Fr}$ - $\mathrm{H} 1$ and $\mathrm{Fr}$ - $\mathrm{H} 2$. Plant J 51:308-321

Szücs P, Karsai I, von Zitzewitz J, Mészáros K, Cooper LLD, Gu YQ, Chen THH, Hayes PM, Skinner JS (2006) Positional relationships between photoperiod response QTL and photoreceptor and vernalization genes in barley. Theor Appl Genet 112:12771285

Szücs P, Skinner JS, Karsai I, Cuesta-Marcos A, Haggard KG, Corey AE, Chen THH, Hayes PM (2007) Validation of the VRN-H2/VRN-H1 epistatic model in barley reveals that intron length variation in $V R N-H 1$ may account for a continuum of vernalization sensitivity. Mol Genet Genomics 277:249-261

Szűcs P, Filichkin T, Cuesta-Marcos A, Hayes PM, Barley CAP (2008) Allele structure of the vernalization and photoperiod loci in the barley CAP Core Germplasm Array. Plant \& Animal Genome XV Conference, January 12-16, San Diego, CA, USA.

Szücs P, Blake VC, Bhat PR, Chao S, Close TJ, Cuesta-Marcos A, Muehlbauer GJ, Ramsay L, Waugh R, Hayes PM (2009) An integrated resource for barley linkage map and malting quality QTL alignment. Plant Genome 2:1-7 
Trevaskis B, Hemming MN, Dennis ES, Peacock WJ (2007) The molecular basis of vernalization-induced flowering in cereals. Trends Plant Sci 12:352-357

Turner A, Beales J, Faure S, Dunford RP, Laurie DA (2005) The pseudo-response regulator Ppd-H1 provides adaptation to photoperiod in barley. Science 310:10311034

von Zitzewitz, J, Szücs P, Dubcovsky J, Yan L, Francia E, Pecchioni N, Casas A, Chen THH, Hayes PM, Skinner JS (2005) Molecular and structural characterization of barley vernalization genes. Plant Mol Biol 59:449-467

Watson L, Henry RJ (2005) Microarray analysis of gene expression in germinating barley embryos (Hordeum vulgare L.). Funct Integr Genomics 5:155-162

White J, Pacey-Miller T, Crawford A, Cordeiro G, Barbary D, Bundock P, Henry R (2006) Abundant transcripts of malting barley identified by serial analysis of gene expression (SAGE). Plant Biotech J 4:289-301

Wesenberg DM, Baenzinger PS, Rasmusson DC, Burrup DE, Jones BL (1998) Registration of 88Ab536-B barley germplasm. Crop Sci 38:559

Yasuda S, Hayashi J, Moriya I (1993) Genetic constitution for spring growth habit and some other characters in barley cultivars in the Mediterranean coastal regions. Euphytica 70:77-83

Yan L, Loukoinov A, Blechl AE, Tranquilli G, Ramakrishna W, Sanmiguel P, Bennetzen JL, Echenique V, Dubcovsky J (2004) The wheat VRN2 gene is a flowering repressor down-regulated by vernalization. Science 303:1640-1644

Yan L, Fu D, Li C, Blechl A, Tranquilli G, Bonafede M, Sanchez A, Valarik M, Yasuda $\mathrm{S}$, Dubcovsky J (2006) The wheat and barley vernalization gene VRN3 is an orthologue of FT. Proc Natl Acad Sci USA 103:19581-19586 
Table 1 Malting quality characteristics of Morex and 88Ab536. Means and standard deviations for each of the seven malting quality traits are shown. (a) Malting quality data summaries of Morex and 88Ab536 grown in Aberdeen, Idaho, during crop years 2003 to 2006. (b) Historic malting quality data for Morex (Crookston, MN) and 88Ab536 (Corvallis, OR) for crop years 2001 to 2005 from locations at which the grain for the microarray experiments were produced. (c) Malting quality data for Morex and 88Ab536 (three biological replicates each) from the malting run used for microarray experiments

A.

\begin{tabular}{l|rrrrrrr}
\hline & ME (\%) & GP (\%) & SP (\%) & S/T (\%) & DP ( ${ }^{\circ}$ ASBC) & AA (20 DU) & BG (ppm) \\
\hline Morex & $78.7 \pm 2.1$ & $13.1 \pm 1.8$ & $5.16 \pm 0.48$ & $41.5 \pm 4.8$ & $157 \pm 37$ & $60.3 \pm 8.2$ & $216 \pm 113$ \\
88Ab536 & $78.5 \pm 1.6$ & $12.9 \pm 1.7$ & $5.20 \pm 0.76$ & $41.9 \pm 4.3$ & $147 \pm 23$ & $65.0 \pm 10.0$ & $235 \pm 61$ \\
Guideline & $>79 \%$ & $\leq 13.5 \%$ & $5.2-5.7 \%$ & $42-47 \%$ & $>140$ & $>50$ & $<120$ \\
\hline
\end{tabular}

B.

\begin{tabular}{l|rrrrrrr}
\hline & ME (\%) & GP (\%) & SP (\%) & S/T (\%) & DP ( ${ }^{\circ}$ ASBC) & AA (20 ${ }^{\circ}$ DU) & BG (ppm) \\
\hline Morex & $77.9 \pm 1.2$ & $14.2 \pm 0.7$ & $5.84 \pm 0.84$ & $42.4 \pm 5.6$ & $162 \pm 17$ & $67.5 \pm 4.5$ & $214 \pm 116$ \\
88Ab536 & $78.0 \pm 1.9$ & $11.6 \pm 0.8$ & $4.73 \pm 0.65$ & $43.4 \pm 5.7$ & $135 \pm 22$ & $65.1 \pm 5.3$ & $213 \pm 95$ \\
\hline
\end{tabular}

C.

\begin{tabular}{l|rrrrrrr}
\hline & ME (\%) & GP (\%) & SP (\%) & S/T (\%) & DP ( ${ }^{\circ}$ ASBC) & AA (20DU) & BG (ppm) \\
\hline Morex & $77.6 \pm 0.3$ & $14.2 \pm 0.0$ & $5.58 \pm 0.04$ & $40.3 \pm 0.0$ & $173 \pm 5$ & $71.5 \pm 2.0$ & $199 \pm 20$ \\
88Ab536 & $77.0 \pm 0.3$ & $11.7 \pm 0.0$ & $4.70 \pm 0.08$ & $42.1 \pm 0.7$ & $127 \pm 6$ & $63.7 \pm 2.6$ & $215 \pm 19$ \\
\hline
\end{tabular}

$M E$ malt extract, $G P$ grain protein content, $S P$ wort soluble protein, $S / T$ ratio of wort soluble protein to total malt protein, $D P$ diastatic power, $A A$ alpha-amylase activity, $B G$ malt beta-glucan content.

Guideline AMBA Ideal Commercial Malt Breeding Guidelines for 6-row barley varieties (see http://www.ambainc.org/ni/Guidelines.pdf, accessed July 7, 2009). 
Table 2 Malting quality and winter hardiness QTL aligned on the 88Ab536 graphical haplotype (Figure 2). Locus designations from pilot OPAs and map positions are also shown. Names of QTL as they appear at the GrainGenes website (http://wheat.pw.usda.gov/ggpages/maps/OWB/) are added in parentheses

\begin{tabular}{|c|c|c|c|c|}
\hline Chrom. & QTL & Trait & Pilot OPA & Position (cM) \\
\hline \multirow[t]{2}{*}{$1 \mathrm{HS}$} & AA (QAa.HaTR-1H.1) & Alpha-amylase activity & 3_0933 & 6.0 \\
\hline & GP (QGpc.DiMo-1H) & Grain protein content & 3_0955 & 15.3 \\
\hline \multirow[t]{4}{*}{$1 \mathrm{HL}$} & PPD-H2 & Photoperiod-H2 & 3_1526 & 112.9 \\
\hline & BG (QBgnm.StMo-1H.2) & Malt beta-glucan content & 1_0207 & 126.5 \\
\hline & ME (QFge.HaTR-1H.2) & Malt extract & 3_1387 & 127.4 \\
\hline & AA (QAa.StMo-1H) & Alpha-amylase activity & 1_0041 & 135.6 \\
\hline \multirow[t]{3}{*}{$2 \mathrm{HS}$} & ME (QMe.StMo-2H.2) & Malt extract & 3_0775 & 10.1 \\
\hline & GP (QGpc.HaMo-2H.1) & Grain protein content & 2_1261 & 28.4 \\
\hline & PPD-H1 & Photoperiod-H1 & 2_1304 & 33.7 \\
\hline \multirow[t]{6}{*}{$2 \mathrm{HL}$} & DP (QDp.StMo-2H) & Diastatic power & 1_0883 & 59.2 \\
\hline & AA (QAa.StMo-2H.1) & Alpha-amylase activity & 1_1388 & 78.0 \\
\hline & GP (QGpc.StMo-2H.2) & Grain protein content & 1_1307 & 96.8 \\
\hline & Flt-2L & Flowering time-2L & 2_0511 & 120.8 \\
\hline & $\mathrm{HD}$ & Heading Time & 3_0041 & 127.6 \\
\hline & GP (QGpc.StMo-2H.3) & Grain protein content & 2_0943 & 149.6 \\
\hline $3 \mathrm{HS}$ & BG (QBgnm.HaTR-3H.1) & Malt beta-glucan content & 3_0431 & 35.2 \\
\hline \multirow[t]{4}{*}{ 3HL } & GP (QGpc.StMo-3H.1) & Grain protein content & 2_1163 & 80.9 \\
\hline & AA (QAa.StMo-3H) & Alpha-amylase activity & 3_0090 & 97.7 \\
\hline & DP (QDp.StMo-3H) & Diastatic power & 2_0662 & 130.8 \\
\hline & S/T (QS/T.DiMo-3H) & Soluble/Total protein & 1_1328 & 138.8 \\
\hline \multirow[t]{5}{*}{$4 \mathrm{HS}$} & BG (QBgnm.StMo-4H) & Malt beta-glucan content & 2_0274 & 7.1 \\
\hline & DP (QDp.StMo-4H) & Diastatic power & 3_0150 & 18.0 \\
\hline & AA (QAa.StMo-4H.1) & Alpha-amylase activity & 2_0557 & 20.1 \\
\hline & GP (QGpc.DiMo-4H) & Grain protein content & 3_0187 & 42.50 \\
\hline & GP (QGpc.HaTR-4H.1) & Grain protein content & 3_0993 & 43.8 \\
\hline \multirow[t]{4}{*}{$4 \mathrm{HL}$} & AA (QAa.StMo-4H.2) & Alpha-amylase activity & 2_0197 & 81.7 \\
\hline & GP (QGpc.StMo-4H) & Grain protein content & 3_0584 & 96.6 \\
\hline & $\begin{array}{l}\text { VRN-H2 } \\
\text { (OSU_VRN_H2_ZCCT_Ha_1430) }\end{array}$ & Vernalization-H2 & 1_0387 & 119.8 \\
\hline & DP (QDp.DiMo-4H) & Diastatic power & 3_0824 & 125.4 \\
\hline \multirow[t]{4}{*}{$5 \mathrm{HS}$} & GP (QGpc.HaTR-5H) & Grain protein content & 3_0163 & 0 \\
\hline & ME (QFge.HaTR-5H.1) & Malt extract & 2_1221 & 9.3 \\
\hline & AA (QAa.DiMo-5H) & Alpha-amylase activity & 1_0580 & 35.7 \\
\hline & DP (QDp.StMo-5H) & Diastatic power & 3_1492 & 47.4 \\
\hline \multirow[t]{6}{*}{$5 \mathrm{HL}$} & AA (QAa.ChHa-5H) & Alpha-amylase activity & 2_0403 & 105.2 \\
\hline & Fr-H2/CBF (OSU_HVCBF12_520) & $\begin{array}{l}\text { Frost resistance-H2/ C- } \\
\text { repeat Binding Factors }\end{array}$ & 3_0846 & 108.2 \\
\hline & BG (QBgnm.HaTR-5H.1) & Malt beta-glucan content & 1_1472 & 132.5 \\
\hline & $\begin{array}{l}\text { Fr-H1/VRN-H1 } \\
\text { (OSU_VRN_H1_BM5A_intron1_vc_80) }\end{array}$ & $\begin{array}{l}\text { Frost resistance-H1/ } \\
\text { Vernalization-H1 }\end{array}$ & 1_0783 & 135.7 \\
\hline & GP (QGpc.DiMo-5H.2) & Grain protein content & 1_0104 & 146 \\
\hline & AA (QAa.HaTR-5H.2) & Alpha-amylase activity & 1_0322 & 196.1 \\
\hline $6 \mathrm{HL}$ & AA (QAa.StMo-6H) & Alpha-amylase activity & 2_1216 & 55.4 \\
\hline
\end{tabular}




\begin{tabular}{lllll}
\multirow{3}{*}{ 7HS } & DP $($ QDp.StMo-6H) & Diastatic power & 2_0714 & 67 \\
& VRN-H3 (OSU_VRN_H3_HvFT1_585) & Vernalization-H3 & 3_0895 & 37.6 \\
& AA (QAa.StMo-7H.3) & Alpha-amylase activity & 3_0880 & 61.3 \\
7HL & BG (QBgnm.StMo-7H.2) & Malt beta-glucan content & 1_0721 & 62.9 \\
& GP (QGpc.HaMo-7H) & Grain protein content & 2_1409 & 87.2 \\
& GP (QGpc.DiMo-7H) & Grain protein content & 2_0406 & 108.7 \\
& DP (QDp.HaTR-7H) & Diastatic power & 1_0861 & 133.8 \\
& AA (QAa.HaTR-7H) & Alpha-amylase activity & 3_1491 & 143.7 \\
\hline
\end{tabular}

$M E$ malt extract, $G P$ grain protein content, $S / T$ ratio of wort soluble to total malt protein, $D P$ diastatic power, $A A$ alpha-amylase activity, $B G$ malt beta-glucan content 
Table 3 Differentially expressed genes between 88Ab536 and Morex at time point "out of steep". Asterisks indicate genes also found to be differentially expressed at " $3 \mathrm{~d}$ of germination"

\begin{tabular}{|c|c|c|c|c|c|}
\hline Probe set & $\begin{array}{l}\text { Fold change } \\
\text { (88Ab536 vs } \\
\text { Morex) }\end{array}$ & Regulation & $E$ value & Putative function & $\begin{array}{l}\text { Map } \\
\text { location }^{a}\end{array}$ \\
\hline Contig8119_at & 1451.42 & up & - & No hit & \\
\hline Contig11923_at & 1207.13 & up & $2.00 \mathrm{E}-35$ & Retrotransposon protein & \\
\hline Contig3707_at* & 767.23 & up & $1.00 \mathrm{E}-180$ & $\begin{array}{l}\text { TMS membrane protein/tumour } \\
\text { differentially expressed protein (TDE) }\end{array}$ & \\
\hline Contig7247_at* & 503.13 & up & $4.00 \mathrm{E}-40$ & Protein csAtPR5 & \\
\hline HS07008u_x_at & 228.20 & up & - & No hit & \\
\hline Contig14284_at & 200.13 & up & $5.00 \mathrm{E}-34$ & Retrotransposon protein & \\
\hline Contig3780_x_at & 92.88 & down & $3.00 \mathrm{E}-45$ & Lipid transfer protein-like protein & \\
\hline Contig2060_s_at & 72.40 & up & $9.00 \mathrm{E}-45$ & Early nodulin protein & \\
\hline Contig10109_at & 59.88 & up & $8.00 \mathrm{E}-61$ & Heat shock factor protein HSF8 & \\
\hline HVSMEI0003B06r2_at* & 51.90 & down & - & No hit & \\
\hline Contig8490_at & 44.51 & up & $1.00 \mathrm{E}-172$ & Protein monooxygenase & \\
\hline Contig3017_at & 38.52 & down & $1.00 \mathrm{E}-118$ & Oxalate oxidase GF-2.8 precursor & $\begin{array}{l}4 \mathrm{H} \\
(21.6 \mathrm{cM})\end{array}$ \\
\hline rbags22p06_s_at* & 37.18 & up & - & No hit & \\
\hline Contig350_x_at & 35.04 & down & $1.00 \mathrm{E}-59$ & Histone $\mathrm{H} 2 \mathrm{~A}$ & $\begin{array}{l}7 \mathrm{H} \\
(136.6 \mathrm{cM})\end{array}$ \\
\hline Contig18336_at & 29.65 & up & $4.00 \mathrm{E}-87$ & Mitochondrial glycoprotein & \\
\hline HU11024u_at & 22.52 & up & $2.00 \mathrm{E}-20$ & Unknown & \\
\hline Contig4028_x_at & 19.80 & down & $6.00 \mathrm{E}-29$ & Unknown & \\
\hline Contig2243_at & 19.65 & down & $1.00 \mathrm{E}-48$ & Hypothetical protein wrsi5-1 & \\
\hline HI02J18u_at & 17.38 & up & $1.00 \mathrm{E}-11$ & Cytokinin-N-glucosyltransferase 1 & \\
\hline Contig17647_at* & 16.00 & up & $2.00 \mathrm{E}-29$ & Os08g0100400 protein & \\
\hline Contig13847_s_at & 15.29 & up & $3.00 \mathrm{E}-85$ & Subtilisin-like serine protease & \\
\hline Contig8511_at & 13.48 & up & - & No hit & \\
\hline Contig18232_at & 12.07 & down & $4.00 E-39$ & Os01g0896300 protein & \\
\hline Contig4009_at & 8.57 & down & 0 & Enoyl-ACP reductase & \\
\hline HVSMEf0016E08r2_at & 8.02 & down & - & No hit & \\
\hline EBpi01_SQ001_L06_at & 7.89 & down & - & No hit & \\
\hline Contig2899_s_at & 6.49 & down & $1.00 \mathrm{E}-163$ & Jasmonate induced protein & \\
\hline Contig6093_at & 6.46 & up & $1.00 \mathrm{E}-108$ & Seed maturation protein & $\begin{array}{l}5 \mathrm{H} \\
(146.0 \mathrm{cM})\end{array}$ \\
\hline Contig26251_at & 6.10 & up & $3.00 \mathrm{E}-14$ & protein retrotransposon protein & \\
\hline HVSMEb0009H14r2_x_at & 5.85 & down & $1.00 \mathrm{E}-39$ & Wali3 protein & \\
\hline Contig2967_at & 5.63 & down & $1.00 \mathrm{E}-157$ & Expansin EXPB9 & \\
\hline Contig5946_at & 4.61 & up & $9.00 \mathrm{E}-55$ & Embryonic protein DC-8 & $\begin{array}{l}4 \mathrm{H} \\
(82.4 \mathrm{cM})\end{array}$ \\
\hline Contig26482_at & 4.54 & down & - & No hit & \\
\hline Contig20856_at & 4.29 & down & $4.00 \mathrm{E}-16$ & Unknown & \\
\hline HVSMEk0003I10r2_x_at & 3.90 & up & $2.00 \mathrm{E}-22$ & Low molecular weight oleosin & \\
\hline Contig8368_at & 3.70 & up & $1.00 \mathrm{E}-135$ & Succinate dehydrogenase & \\
\hline HV14C07u_at & 3.68 & down & $1.00 \mathrm{E}-21$ & Unknown & \\
\hline Contig7672_at & 3.16 & up & $1.00 \mathrm{E}-137$ & Protein phosphatase $2 \mathrm{C}$ (PP2C) & \\
\hline Contig18163_s_at & 2.56 & up & $9.00 \mathrm{E}-22$ & Unknown & \\
\hline Contig7373_at & 2.18 & up & $8.00 \mathrm{E}-30$ & Protein SEP2 & \\
\hline
\end{tabular}

\footnotetext{
${ }^{a}$ Map locations determined from http://harvest.ucr.edu
} 
Table 4 Differentially expressed genes between 88Ab536 and Morex at time point " $3 \mathrm{~d}$ of germination". Asterisks indicate genes also found to be differentially expressed at time point "out of steep"

\begin{tabular}{|c|c|c|c|c|c|}
\hline Probe set & $\begin{array}{l}\text { Fold change } \\
\text { (88Ab536 vs } \\
\text { Morex) }\end{array}$ & Regulation & $E$ value & Putative function & $\begin{array}{l}\text { Map } \\
\text { location }^{a}\end{array}$ \\
\hline Contig3707_at* & 927.71 & up & $1.00 \mathrm{E}-180$ & $\begin{array}{l}\text { TMS membrane protein/tumour differentially } \\
\text { expressed protein (TDE) }\end{array}$ & \\
\hline Contig2905_s_at & 658.05 & up & $1.00 \mathrm{E}-152$ & Jasmonate induced protein & \\
\hline EBma03_SQ003_L08_s_at & 525.54 & up & $2.00 \mathrm{E}-73$ & Caffeic acid O-methyltransferase & \\
\hline Contig30_at & 481.82 & up & $3.00 \mathrm{E}-53$ & Histone H4 & \\
\hline Contig119_at & 358.20 & up & $1.00 \mathrm{E}-59$ & Histone $\mathrm{H} 2 \mathrm{~A}$ & \\
\hline Contig1177_at & 331.72 & up & $5.00 \mathrm{E}-61$ & Histone H2B.5 & \\
\hline Contig7247_at* & 208.97 & up & $4.00 \mathrm{E}-40$ & Protein csAtPR5 & \\
\hline HT07L18u_at & 125.17 & down & - & No hit & \\
\hline rbags22p06_s_at* & 80.11 & up & - & No hit & \\
\hline Contig124_at & 66.71 & up & $2.00 \mathrm{E}-70$ & Histone H3 & \\
\hline Contig6006_s_at & 60.75 & up & 0 & Unknown & $\begin{array}{l}7 \mathrm{H} \\
(0.6 \mathrm{cM})\end{array}$ \\
\hline HVSMEI0003B06r2_at* & 56.10 & down & - & No hit & \\
\hline Contig2905_at & 55.70 & up & $1.00 \mathrm{E}-113$ & Jasmonate induced protein & \\
\hline HS05N24u_s_at & 53.77 & up & 0 & Vacuolar sorting receptor 1 & $\begin{array}{l}5 \mathrm{H} \\
(53.2 \mathrm{cM})\end{array}$ \\
\hline Contig17647_at* & 21.07 & up & $2.00 \mathrm{E}-29$ & Os08g0100400 protein & \\
\hline Contig10883_at & 17.33 & up & 0 & Vacuolar sorting receptor 1 & $\begin{array}{l}5 \mathrm{H} \\
(53.2 \mathrm{cM})\end{array}$ \\
\hline Contig14738_at & 11.80 & up & $1.00 \mathrm{E}-114$ & Integral membrane protein & \\
\hline Contig1143_at & 7.20 & up & 8.00E-70 & Histone H2B.2 & \\
\hline HVSMEI0007F21r2_s_at & 6.31 & down & - & No hit & \\
\hline Contig8732_at & 3.28 & up & $5.00 \mathrm{E}-60$ & $15.9 \mathrm{kDa}$ subunit of RNA polymerase II & \\
\hline Contig20388_at & 3.03 & up & $1.00 \mathrm{E}-114$ & Unknown & \\
\hline
\end{tabular}

${ }^{\text {a }}$ Map locations determined from http://harvest.ucr.edu 
Figure 1 Barley seeds of Morex and 88Ab536 at time points "Out of steep" and " $3 \mathrm{~d}$ of germination" of the malting process
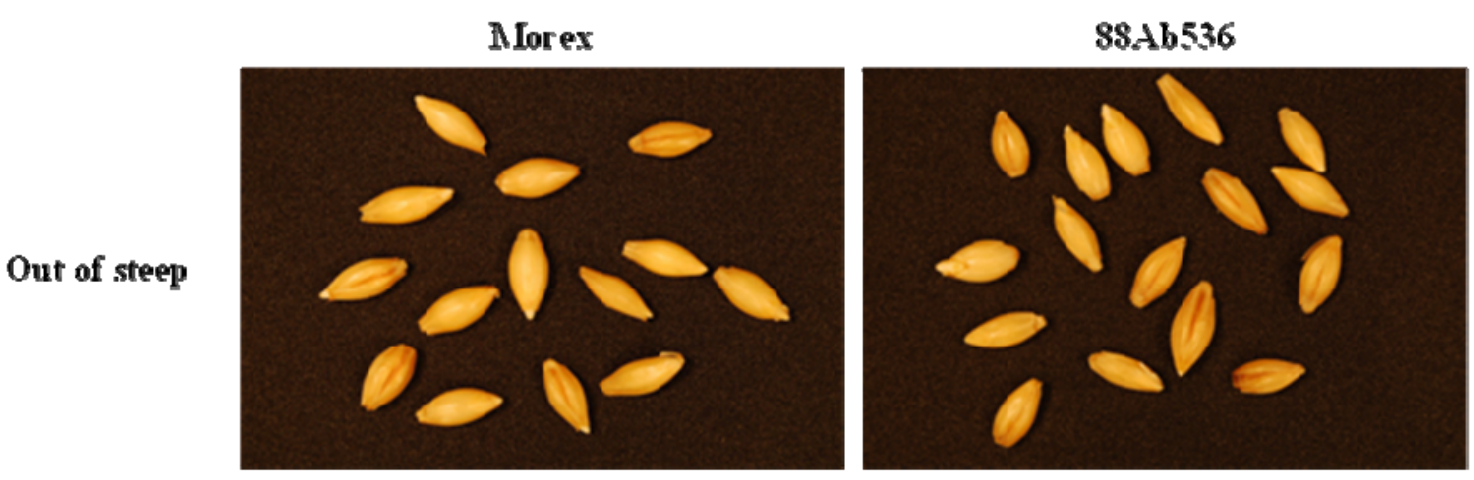

3d of germination
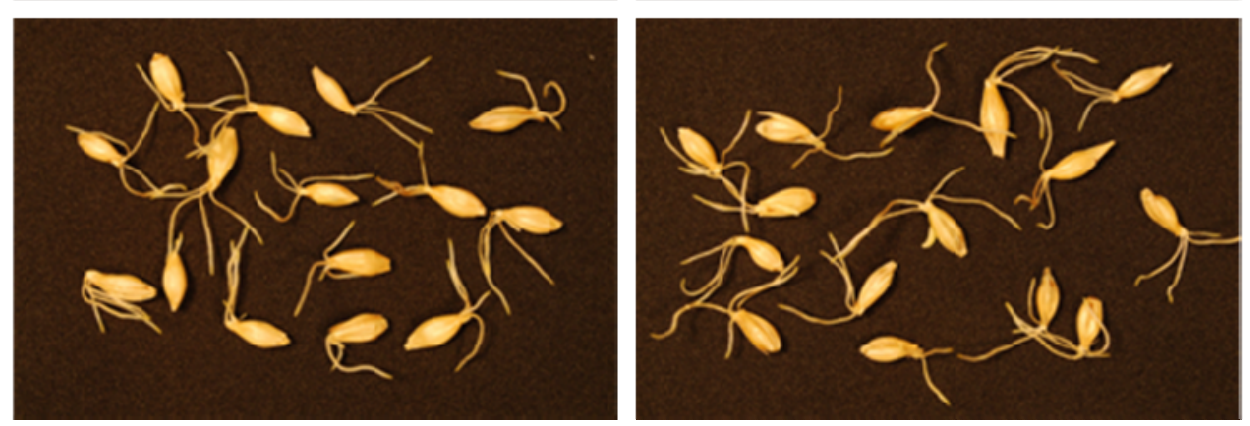
Figure 2 Haplotype structure of 88Ab536. Regions that traces to Morex are colored in blue, while the red color represents regions that are derived from NE76129. Regions that are likely to come from the Nebraska parent are colored in pink. Map locations without a marker are colored in white. QTL of malting quality and winter hardiness traits are aligned. Differentially expressed genes with know map locations have been added to the 88Ab536 haplotype. $M E$ malt extract, $G P$ grain protein content, $S / T$ ratio of wort soluble to total malt protein, $D P$ diastatic power, $A A$ alpha-amylase activity, $B G$ malt beta-glucan content

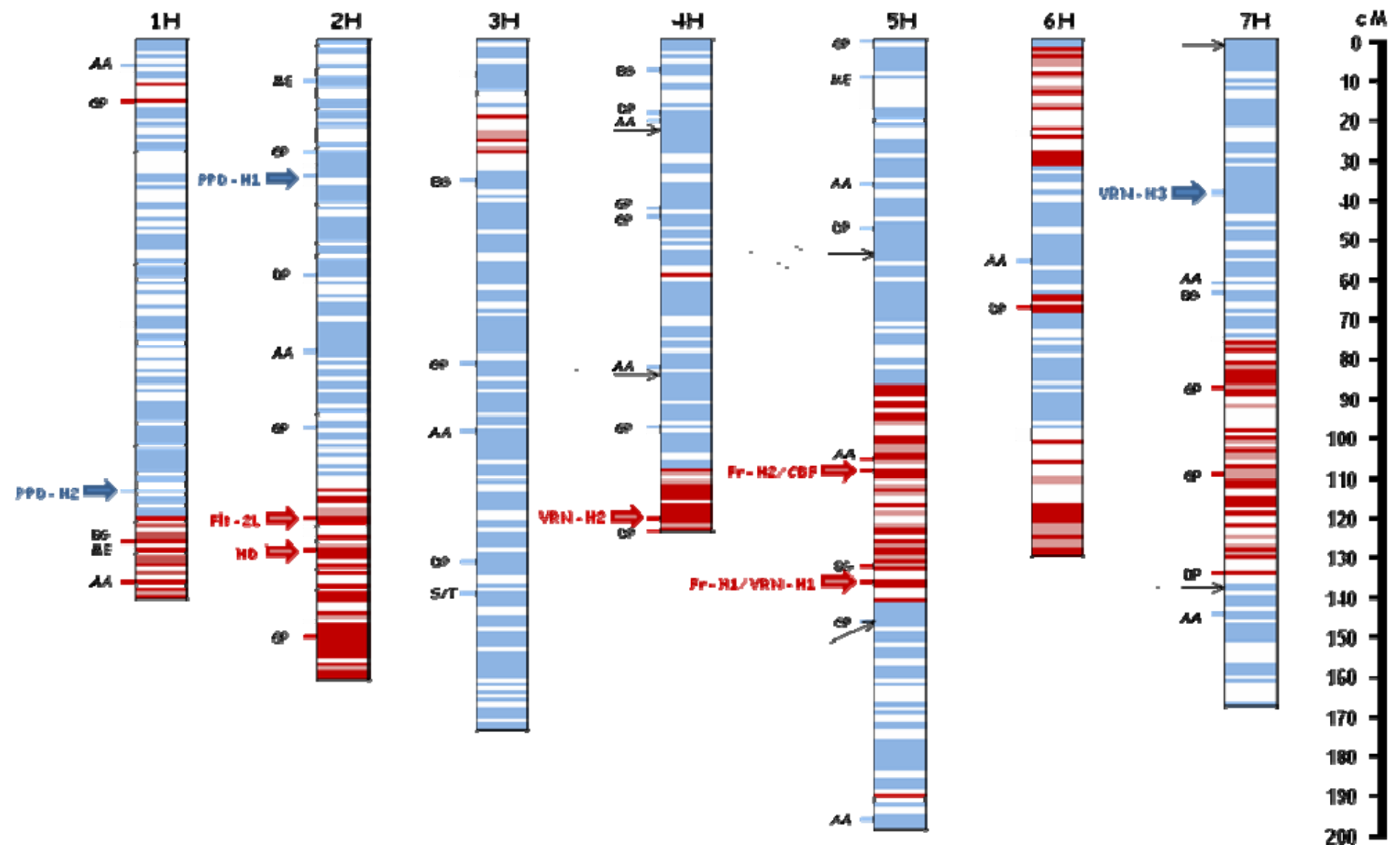

